\title{
Fusion of a Maxillary Central Incisor with a Supernumerary Tooth
}

\author{
by \\ Makoto YUZAWA, Yoshiaki AKIMOTO, Hiroaki OMATA, \\ Takeo NAKAMURA, Kenji KANEKO and Hirotsugu YAMAMOTO*
}

(Received 15 October 1985)

\section{Introduction}

Anomaly of tooth shape is sometimes found in dental practice. Anomaly has been found at the crown as well as at the root, with various types of morphology ${ }^{[1-3]}$. Reported here is a unique case of a fused tooth showing a "Y" shape.

\section{Case report}

A 12-year-old boy presented at the Department of Oral Surgery, Nihon University Dental Hospital at Matsudo, with an unsightly appearance caused by lack of a maxillary central incisor. The complaint was made by his parents. Oral examination revealed uneruption of the maxillary left central incisor and eruption of a supernumerary tooth (approximately $2 \mathrm{~mm}$ in diameter) on the palatal mucosa lateral and posterior to the incisive papilla (Fig. 1). Radiographs demonstrated

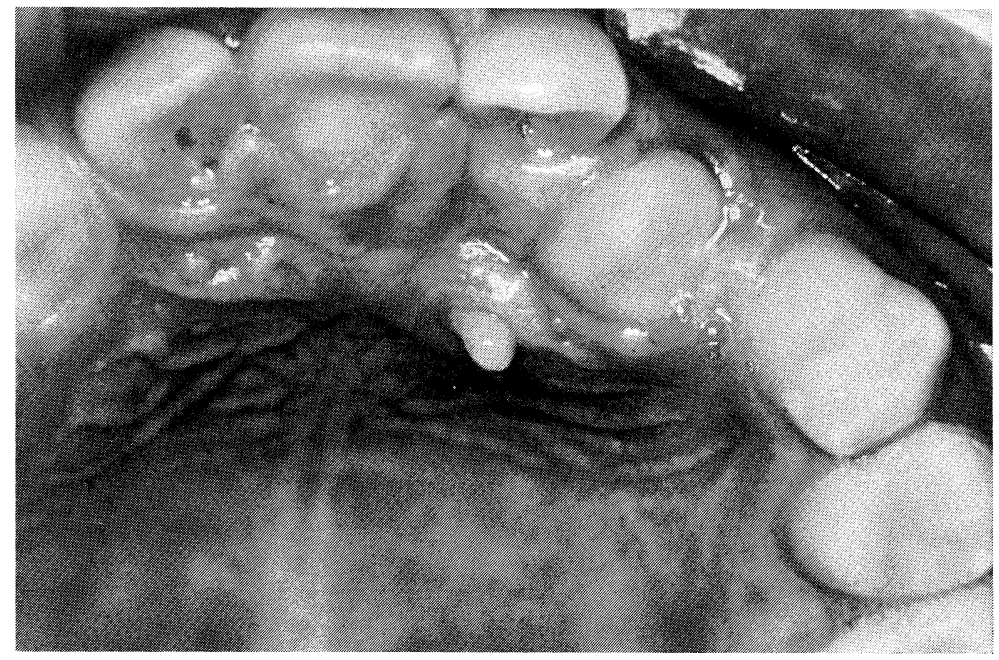

Fig. 1 The crown of the fused tooth on the palatal mucosa

湯澤 眞, 秋元芳明, 小俣裕昭, 中村武夫, 金子賢司, 山本浩嗣*：Second Department of Oral Surgery, Department of Clinical Pathology*, Nihon University School of Dentistry at Matsudo, 2-870-1, Sakaecho-Nishi, Matsudo, Chiba, 271, Japan 
the existence of both the unerupted central incisor and the supernumerary tooth (Figs. 2 and 3). The teeth were fused to each other at the root and cervical regions to form a Y-like shape. Only part of the crown of the supernumerary tooth appeared on the palatal mucosa. Since the fused tooth was located just beneath the palatal mucosa, it was easily extracted only by incision of the mucosa. The original form of the fused tooth and its radiograph are shown in Figs. 4 and 5, respectively. The radiograph demonstrated confluence of the pulp chambers, and histological examination showed more clearly that the fusion involved the enamel, dentine, and pulp chamber of both the incisor and supernumerary tooth.

\section{Discussion}

Fused teeth are relatively rare, and are mostly mandibular frontal teeth, for example, fusion of central and lateral incisors or a lateral incisor and a cuspid ${ }^{[4-6]}$. Fusion of normal and supernumerary teeth occurs with less frequency than fusion between normal teeth. HACHISUKA ${ }^{[7]}$ has reported that the frequency of occurrence of fusion between normal and supernumerary teeth is $0.1 \%$, and that this type of fusion mostly involves maxillary frontal teeth.

SHAFER $^{[5]}$ has reported that physical force or pressure can cause developing teeth to come into contact, resulting in their subsequent fusion. If this contact occurs early, at least before the start of calcification, the two teeth may be completely united to form a single large tooth. If tooth contact occurs after the time when a portion of the tooth crown has completed its formation, there may be union of the roots only. In the present case, since the crowns were separated, such contact must have

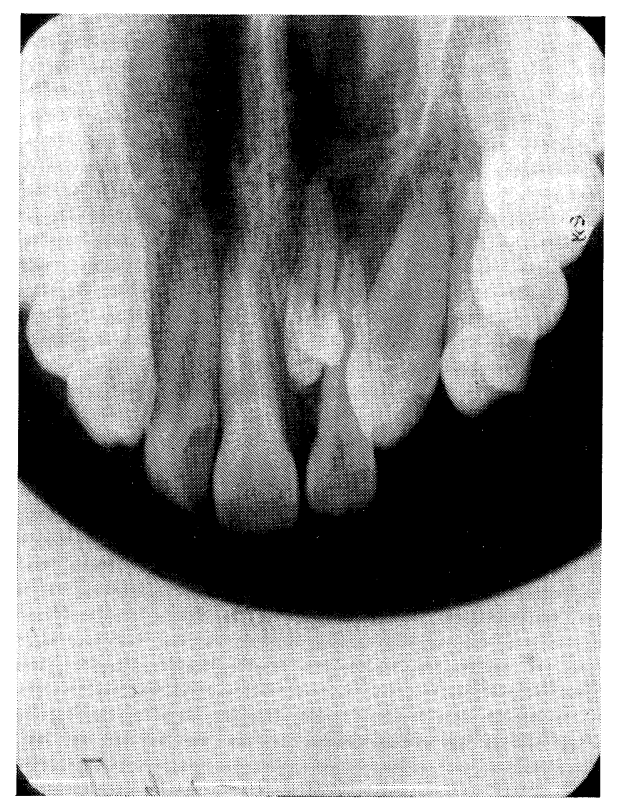

Fig. 2 Radiograph of the fused tooth

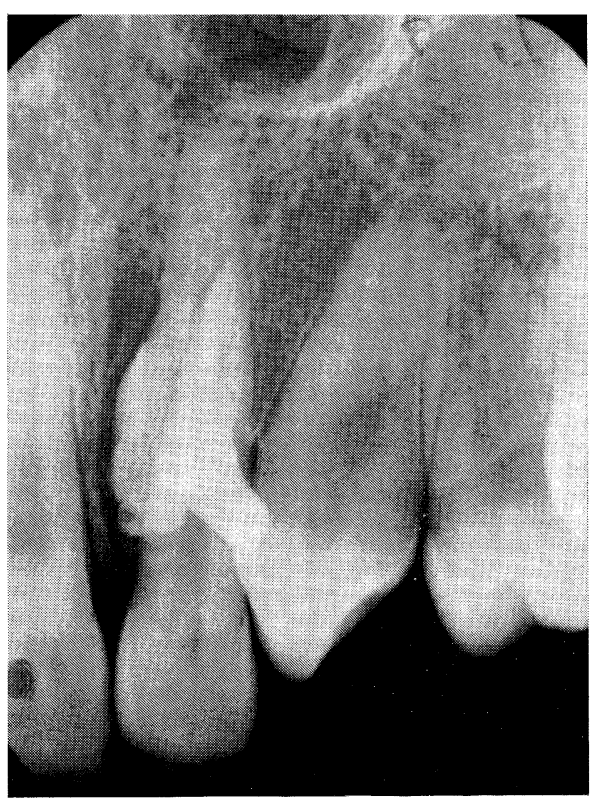

Fig. 3 Radiograph of the fused tooth 


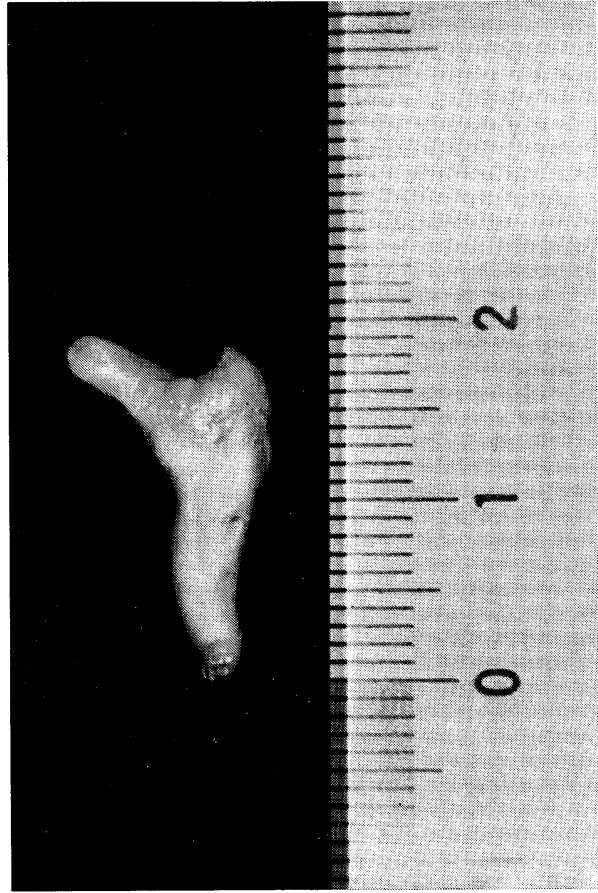

Fig. 4 The extracted "Y"-shaped tooth

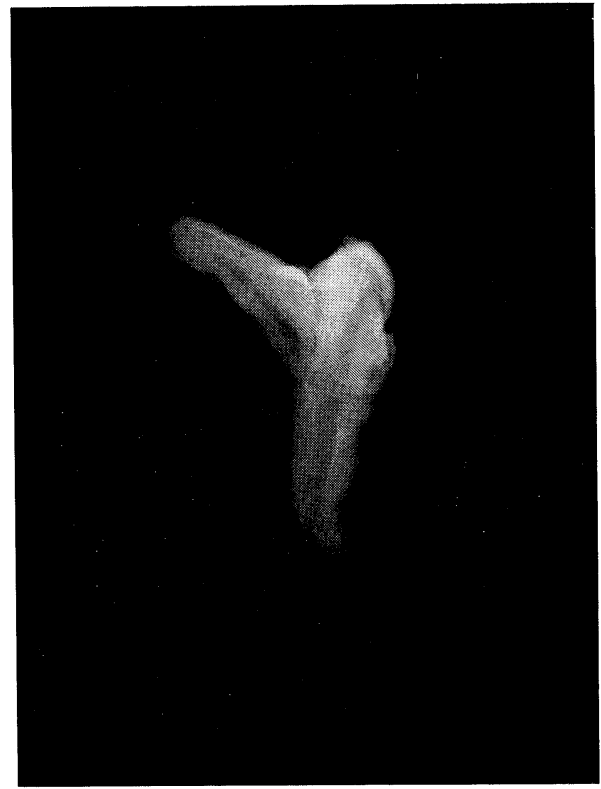

Fig. 5 Radiograph of the extracted tooth demonstrating confluence of the pulp chambers

occurred at a late stage. SHAFER ${ }^{[5]}$ has also reported that some cases show a hereditary tendency to fuse. However, such a tendency was not found in the present case.

\section{Summary}

A Y-shaped tooth, which was caused by fusion of an incisor with a supernumerary tooth, was presented.

\section{References}

[1] Mader, C.L. and Zielke, R.D.: Incomplete dens in dente in a fused tooth, Oral Surg., 53, 439, 1982

[2] Powell, E.R.: Fusion of maxillary lateral incisor and supernumerary tooth, Oral Surg., 51, 331,1981

[3] Fujita, H. and Ohmori, I.: Median incisor fusion, Oral Surg., 57, 578-579, 1984

[4] Gorlin, R.J. and Goldman, H.M.: Developmental abnormalities of the teeth and jaws. In Thoma's Oral Pathology, 6th ed., Vol. I, 96-123, Gorlin, R.J. and Goldman, H.M., Eds., Mosby, St. Louis, 1970

[5] Shafer, W.R., Hine, M.K. and Levy, B.M.: A Textbook of Oral Pathology, 3rd ed., 35-38, Saunders, Philadelphia, 1974

[6] Ishikawa, G. and Akiyoshi, M.: Oral Pathology, 3rd ed., 1-24, Nagasue Shoten, Tokyo, 1978 (in Japanese)

[7] Hachisuka, M.: Fused tooth, J.N.D.A., 33, 117-127, 1940 